\title{
Nutrigenomics and Nutrigenetics in Functional Foods
}

\author{
T. Romero-Cortes, P. A. Lopez-Perez, A. K. M. Toledo, V. H. Perez-Espana, J. E. Aparicio-Burgos and J. A. Cuervo-Parra*
}

Escuela Superior de Apan, Universidad Autonoma del Estado de Hidalgo, Chimalpa Tlalayote (43 900), Mexico

\section{Corresponding Author}

J. A. Cuervo-Parra

e-mail: jalioscha@gmail.com

\author{
Article History \\ Article ID: AR1922 \\ Received in $26^{\text {th }}$ October, 2018 \\ Received in revised form $05^{\text {th }}$ November, 2018 \\ Accepted in final form $12^{\text {th }}$ November, 2018
}

\begin{abstract}
The main function of the diet is to provide the necessary nutrients to meet the nutritional needs of people. Since long, there is evidence that there is a relationship between diet and health and from these arose the concept of functional foods. In general, functional foods are those that not only fulfill a nutritional function but also contain biologically active components that offer health benefits and reduce the risk of suffering diseases. An important key to know the effect that functional foods have on nutrition is to determine how the body responds to the stimulation of these. In other words, the components of the diet can alter genomic expression. However, not all people respond in the same way. A large number of genes from the human genome are induced to code for the proteins involved in the nutritional processes and the induction of these genes is determined by the polymorphisms that each person has in their genome. For example, a diet rich in folic acid prevents the development of cardiovascular diseases related to people who have a polymorphism in exon 4 of the MTHFR gene related to folate metabolism. Therefore, the proposal of this book is to review the current research of Nutrigenomics, which is the study of the effect of nutrients on the expression of genes and Nutrigenetics which is the influence of polymorphisms of people in response to nutrients.
\end{abstract}

Keywords: Functional foods, nutrigenomics, nutrigenetics, omic sciences

\section{Introduction}

The supply of nutrients from food and its use by the body began to be studied long ago, even before the so-called Chemical Revolution (Fujii et al., 2010). It is believed that the science of nutrition emerged from that moment, as no scientific research had been done before (Carpenter, 2003a). Until 1885, studies on nutrition had been conducted in Western Europe and the greatest interest was in the energy and protein needs (Fujii et al., 2010). This line of research continued for a few more years, subsequently expanding to other parts of the world where important research was developed, a fact that promoted the understanding of the nutritional needs of people (Carpenter, 2003b).

Since then, researchers obtained results that have allowed us to see the nutritional problems that humanity has faced in the history course (Carpenter, 2003c). Later, at the beginning of the 20th century, nutritional deficiencies such as anemia, beriberi, rickets, xerophthalmia and pellagra were related to the certain nutrients (Fujii et al., 2010). These findings are essential to know what happened in the "age of vitamins" also called "golden age of nutrition" (Carpenter, 2003d). Later, by the 1940s, practically all the nutrients that are known today and their applications had already been discovered (Ordovas and Carmena, 2005).

The diet rich in saturated fats and cholesterol, suffered great impact during the Second World War, due to food restriction. This fact, allowed the scientists to make the association between the consumption of saturated fats and cholesterol, and the reduction of ischemic heart disease, as well as an improvement of the available drugs and the smoking less (Fujii et al., 2010). However, overweight accompanied by diabetes persisted for a while as the science of nutrition was not yet ready to intervene in shape and cope with the consequences of a sedentary lifestyle. Thus, since 1945, chronic noncommunicable diseases such as cardiovascular diseases and diabetes mellitus have become issues of concern for nutrigenomics (Carpenter, 2003d). Currently, scientific advances have led us to the "Genomic Revolution" (Ordovás and Mooser, 2004). Therefore, nutrigenomics is a recent science that investigates the various interactions of genes with nutrients (Clavijo and Fajardo, 2008).

\section{Past, Present and Future of Nutrigenomics}

During the last 220 years of research in the field of nutrition, we have gone through the chemical revolution and the golden 
age of nutrition and, we are moving to a genomic revolution (Ordovas and Carmena, 2005). The World Health Organization estimates that dietary factors influence more than two thirds of diseases (Svacina, 2007). With the use of nutrigenomics can be defined diet in the future, what we might call a genetic passport. It is clear the enormous potential that the knowledge of the human genome can have in the feeding patterns, but it will not be less the one that has the sequencing of the genomes of other living organisms of agrifood interest (Vidal, 2009).

Nutrigenomics science studies the way in which DNA and our genetic code are related to nutrients to maintain an optimal state of health (Castle and Ries, 2007). The European Nutrigenomics Organization (NUGO) has the objective of translating nutrigenomics data, in order to make accurate predictions of the beneficial or adverse health effects of dietary components (NUGO, 2004). Therefore, nutrigenomics represents the paradigm of a new approach to research in nutrition, which integrates the application of the powerful technologies of functional genomics (transcriptomics, proteomics, metabolomics), bioinformatics and molecular biology, with epidemiological techniques, nutrition and biochemistry classically established (Palou et al., 2004). Among its essential objectives are to determine the effects and mechanisms by which food, its individual components and combinations, regulate the metabolic processes within the body's cells and tissues, as well as the applications of these new knowledge (Clavijo and Fajardo, 2008).

In the future, the nutrigenomics and psychology, will be to collaborate in the modification of eating habits to achieve healthier lifestyles (Clavijo and Fajardo, 2008). The practical impact of nutritional research on the health of people will lie in the formulation of dietary recommendations made to each individual, with the aim of preventing diseases, promote health and optimal aging (Ordovás and Carmena, 2005).

\subsection{Concepts and implications of nutrigenomics}

The term nutritional genomics or nutrigenomics born in reference to biochemistry or plant metabolism (Gillies, 2003). In the context of human biology, is the relation and the integration between functional genomics, nutrition and health (Marti et al., 2005).

The nutrigenomics implications are: a) actions of the components of the diet, which directly or indirectly, can alter the expression or structure of the genes; $b$ ) in some individuals and under certain circumstances, diet can be a risk factor for a disease; c) some genes regulated by diet (and their common variants) may play a role in the onset, incidence, progression, and or severity of chronic diseases; d) the degree to which diet influences the health-disease binomial may depend on the individual genetic makeup, and e) any dietary intervention based on knowledge of nutritional needs, nutritional status, and genotype will be useful to prevent, mitigate, or cure chronic diseases (Marti et al., 2005).

\subsection{General aspects of the study in nutrigenetics and} nutrigenomics

The evolution of nutritional sciences has varied significantly in recent years. Until recently, research in nutrition and health focused mainly on the deficit or excess of food (Clavijo and Fajardo, 2008). The first draft of the human genome was published in the year 2000 (Rivera, 2002), three years later, in the month of April, the sequence that makes up the human genome was published (Esteva, 2003). We are little more than twenty-three thousand genes interacting with the environment. That molecular alphabet is translated according to our physical or cultural environment. The impact of genomics on our daily lives is evident and this has led to the emergence of two new scientific disciplines: nutrigenetics and nutrigenomics (Vidal, 2009).

The nutrigenomics began to work in the so-called personalized diets (Vakili and Caudill, 2007). The preferences for food are influenced by various factors among which are personal experiences, cultural adaptations and perceived benefits for health (Clavijo and Fajardo, 2008). To these are added biological factors such as taste and smell, topics of interest also for genetics (El-Sohemy, 2007).

The nutrigenetics studies the effect of genetic variations between individuals in the interaction between diet and disease (Vidal, 2009). While, nutrigenomics makes reference to the prospective analysis of the differences between the nutrients with respect to the regulation of the expression of the genes (Marti et al., 2005). In other words, nutrigenomics aims to provide molecular (genetic) knowledge about the components of the diet that contribute to health by altering the expression and or structures according to the individual genetic constitution (Gillies, 2003). Therefore, it is a science rooted in molecular biology, whose tools are microarray technology and computer computing (Marti et al., 2005). On the other hand, nutrigenetics encompasses the retrospective analysis of the genetic variants of individuals that condition the clinical response to nutrients, being therefore an applied science, marked by the paradigms of nutritional pharmacology in relation to polymorphisms and clinical experience (Marti et al., 2005).

\subsection{Molecular nutrition}

A large number of genes in the human genome encode the proteins that mediate and or control the nutritional processes and although part of their information, chromosomal location, structure and function has been compiled, still is not understanding the orderly way in which the metabolism takes place (Marti et al., 2005). Fortunately, with the technological advances, it has been possible to simultaneously analyze a large series of messenger RNA (mRNA) and or proteins expressed in a biological sample or to define the genetic heterogeneity in the individual response of the organism to nutrients (Daniel, 2002). Therefore, the use of new genome analysis techniques will be crucial tools for the development 
of the food and nutrition sciences in the coming decades and their integration in the era of functional genomes (Marti et al., 2005).

\subsubsection{From nutrients to genes}

A basic concept is that the progression from a healthy phenotype to a phenotype of chronic dysfunction can be explained by changes in gene expression or by differences in the activities of proteins and enzymes, and that the components of the diet directly or indirectly regulate the expression of the genetic information (Marti et al., 2005). In this sense, the expression of the genes follows a sequence, in which the relation of the gene expression with the "omic" sciences is observed (Sanhueza and Valenzuela, 2012). The environment is a factor that can act on DNA, RNAs and proteins, causing phenotypic modifications at the chromatin level with implications in the expression or silencing of certain genes (Sanhueza and Valenzuela, 2012). For example, it has been found that by including essential nutrients such as choline, methionine and folates in the diet, methylation of DNA histones is altered by positively influencing birth weight (Killian et al., 2000).

This type of epigenetic (non-genetic) changes, present in some proteins such as histones, contribute to the diversity of phenotypes that occur in different types of human cells (Sanhueza and Valenzuela, 2012). These changes have additive effects that can influence the stability of the genome depending on the size of the modification (Fabiani et al., 2010). In this regard, it has been observed that abnormal DNA methylation triggers chronic autoimmune diseases such as systemic lupus erythematosus or schizophrenia (Abraham et al., 2004). Other suggest that cardiorespiratory fitness (CRF) mitigates brain atrophy related to aging, through a series of beneficial mechanisms (Fletcher et al., 2016). On the other hand, the diet contains elements that modify the formation of specific microRNAs, which can block or increase the growth of cancerous tissue (Saini et al., 2010). Another way in which nutrients can intervene in gene expression, is through specific proteins. These proteins can interact with DNA and or cause post-transcriptional or post-translational modifications (de las Cagigas et al., 2002). How they interact it is by regulating the mRNA level during processing that extracts the introns and exons spliced (Long et al., 1995).

\subsubsection{Genes}

Our genes have adapted to the changes in our ancestors' food sources. This poses new challenges for nutrigenomics (Clavijo and Fajardo, 2008). In fact, it is estimated that the inability of our genome to adapt to modern diets may be associated with the appearance of certain chronic diseases in the civilizations developed (Silleras and Torres, 2000).

So far, more than five hundred different genomes have been fully sequenced and there are more than seven hundred sequencing projects underway. Some of them refer to animals, plants or microorganisms of food relevance, such as, for example, rice, baker's yeast, bacteria Bifidobacterium bifidum used in many probiotic products, or pathogens responsible for food poisoning, such as Escherichia coli (Vidal, 2009). Knowledge of the genes that make up the genome of these organisms will allows to know their key genes in order to establish strategies for improvement by classical genetics (Withee and Dearfield, 2007).

\subsubsection{Interactions between genes and nutrients}

Numerous epidemiological studies confirm the existence of a certain association between the diet ingested by an organism and the incidence and severity of chronic diseases (Stover, 2004), although it is not easy to distinguish which are the bioactive molecules of the food that exert beneficial actions in the organism (Marti et al., 2005).

The components included in the diet can alter genomic expression directly or indirectly. At the cellular level, nutrients can act as ligands for the activation of transcription factors that favor the synthesis of receptors (Marti et al., 2005). Also, they can be metabolized by primary or secondary metabolic routes, thereby altering the concentrations of substrates or intermediates; or influence positively or negatively on signaling routes (Kaput and Rodríguez, 2004). For example, fatty acids are metabolized by the de-oxidation pathway to produce cellular energy (Marti et al., 2005), where the alteration of the intracellular energy balance can indirectly alter the genetic expression through the changes in the homeostasis of the cellular NAD (Lin and Guarente, 2003). The re-oxidation of NAD is associated with the activity of the mitochondrial electron transport chain and is a cofactor for proteins involved in chromosomal remodeling (Lin and Guarente, 2003). On the other hand, the process of chromosomal remodeling has short and long term consequences for genetic regulation through reactions such as acetylation of histones or DNA methylation that alters its access, and therefore its regulation, in eukaryotic organisms (Kaput and Rodriguez, 2004).

\subsubsection{Gene-diet interaction}

The implication of a genetic component as a key part of the differences in dietary response was proposed several decades ago (Holtzman, 1988). However, recently began to examine the gene-nutrient interactions at a molecular scale. Interactions that are dynamic as they begin with procreation and continue throughout the life of an individual (Ordovas and Carmena, 2005). On the other hand, the concept of gene-diet interaction deals with the effect that a component of the diet has on a particular phenotype due to a genetic polymorphism. For example, some molecules in the diet can be ligands for nuclear receptors (Marti et al., 2005) or act in the interactions on lipid metabolism (Loktionov, 2003).

However, not all genes involved in the metabolism of fatty acids, are regulated by one of the three members of the family of peroxisome proliferator-activated receptors. (PPAR $\alpha$, PPAR $\beta$, PPAR $\gamma$ ) (Kaput and Rodriguez, 2004). The fatty acids, palmitic (16:0), oleic (18:1 n6), and arachidonic 
(20:4 n6) and the eicosanoids, 15-deoxy- $\Delta$ (Willett, 2002), prostaglandin $\mathrm{J} 2$ and 8-(S) hydroxyethicosatraenoic acid, were ligands for PPARs (Kliewer et al., 2001). In other words, these nuclear receptors act as sensors for fatty acids, which often heterodimerize with a retinoid $X$ receptor ( $R X R)$. Other components of the diet, such as genistein, vitamin $A$, or hyperforin, bind directly to nuclear receptors and alter gene expression (Marti et al., 2005). Also, some transcription factors are indirectly regulated by the components of the diet; for example, the proteins binding to the sterol regulatory element (SREBPs) are activated by segmentation proteases, an event regulated by low levels of oxysterols, the insulin glucose ${ }^{-1}$ ratio and the levels of polyunsaturated fatty acids (PUFA) (Kaput and Rodríguez, 2004).

The metabolic conversion of the various components of the diet contributes as a mechanism of control of gene expression and the catabolic routes also influence the intracellular concentrations of intermediates and end products (Nobel et al., 2001). Thus, the concentration of any ligand will depend on specific combinations of alleles in genes that encode proteins of enzymatic pathways and the number of heterozygous individuals may vary from one subpopulation to another, which is a basic principle in nutrigenomics (Marti et al., 2005). The components of the diet can directly affect the signal transduction pathways by inhibiting the signaling pathway (Marti et al., 2005). For example, green tea contains polyphenols, such as 11-epigallocatechin-3-gallate (EGCG), which inhibits tyrosine phosphorylation of the Her-2 neu-1 receptor and the epidermal growth factor receptor (EGF) (Kaput and Rodríguez, 2004). Some cereals such as rice contain inositol hexaphosphate, which is able to inhibit cell transformation induced by cell growth factor by its actions on the PI-3 kinase (Dong, 2000).

The human genome is sensitive to the nutritional environment, therefore, some components of the diet play a fundamental role in the regulation of the expression of some genes present in foods of vegetable or animal origin (Marti et al., 2005). In addition, the benefits derived from the use of genomics in the dietary prevention of diseases are large (Mensink and Plat, 2002).

\section{The Omic Sciences}

The approach of a general diet based on the identification, documentation and epidemiology conceived in the past continues to be valid; however, there are other approaches (Clavijo and Fajardo, 2008). In this regard, the omic sciences have allowed the study of a large number of molecules, related to the functioning of a personalized organism (Frigolet and Gutiérrez-Aguilar, 2017). On the other hand, the incorporation of avant-garde technologies that promote the application of the sciences of genetics, genomics and nutrition, is fundamental to promote the development of research in the field of nutrition and detection of chronic diseases related to diet (Perdomo and Cardenas, 2011). With genomics it is possible to detect within a population polymorphisms that allow understanding the predisposition to present some diseases or different responses to drugs, diet, or physical activity among others. In this sense, functional genomics is based, among other aspects, on the nutripharmacology and the bioanalytical profile for achieve a personalized nutrition (Afman and Müller, 2006). Currently, the precision nutrition, consider the characteristics of the individual to achieve a better prevention or treatment of diseases, where the use of omic sciences is fundamental (Corella, 2016).

\subsection{The support of the omic sciences}

The omic sciences were driven by the revelations of the human genome project and the associated technological developments; such as genotyping, transcriptomics, proteomics and metabolomics, among others (García, 2004). For example, genomics is responsible for the study of many genes in DNA, transcriptomics for the study of many transcripts or mRNA, proteomics for the study of many proteins, and metabolomics for the study of many metabolites (Frigolet and Gutierrez-Aguilar, 2017). Reasons why these omics sciences are used in the field of nutrition research. It is hoped that, in the future, the omic sciences will guide the way towards a more personalized nutrition for the benefit of health (Zhang et al., 2008).

The changes in focus in the nutritional study are due to the results derived from scientific research that have shown that the effects of nutrition on health and disease cannot be understood without understanding how nutrients act in the molecular plane (Perdomo and Cardenas, 2011). On the other hand, the discovery of the role of micronutrients and macronutrients as powerful dietary signals that influence the metabolic programming and control of homeostasis at a cellular level (Yaktine and Pool, 2007). These results emanate from a number of genomic projects where nutritional research strategies have been modified by highlighting the importance of genes in human nutrition (Mutch et al., 2005). All of the above, has been recognized that genetic predisposition can be an important factor for the development of diseases linked to diet such as type II diabetes and cancer (Mutch et al., 2005).

At present, the progress and development in genetic material allows to differentiate the molecular structure of each individual, achieving a greater understanding of the genes human (Clavijo and Fajardo, 2008). Also, with the technological progress and analysis tools, it has been possible to increase the number of molecules detected to for interpreting all the data generated (Frigolet and Gutierrez-Aguilar, 2017).

\subsubsection{Genomics}

Prior to the appearance of this first omic science, the existing technology allowed the study of few genes, their changes or mutations (Frigolet and Gutierrez-Aguilar, 2017). Subsequently, with the sequencing of the human genome (Venter et al., 2001), the order that the nucleotides had in the DNA of the human being was deciphered (International 
Human Genome Sequencing Consortium, 2004) and that $99 \%$ of this genome between humans is the same being therefore only $1 \%$ mutations (Frigolet and Gutierrez-Aguilar, 2017). Therefore, genomics is responsible for studying the variations, which occur in a living organism, at the structural level of DNA, gene conformation and population variation of genetic polymorphisms (Clavijo and Fajardo, 2008). It is also responsible for mapping, sequencing and analyzing genomes, which has facilitated the identification and understanding of the forms of organization and function of genes (Burguete et al., 2009).

Genomics, is divided into three parts. In structural genomics, which is responsible for characterizing the physical nature and expression of complete genomes, in functional genomics that studies the mechanisms of action of genes (Hocquette, 2005), and in comparative genomics, which focuses on the comparative study of the structural and functional genomes (López-Lopez et al., 2005). On the other hand, the correlation between genome variations and disease is important to understand, diagnose, treat and even prevent some diseases (Cooper and Psaty, 2003). In this sense, genomics evaluates the effect and interaction of genes and the environment on the health of a population (Burguete et al., 2009). Where, the structure of the population and the forces of selection, have effects on the frequency of genetic traits (Khoury et al., 2004). In addition, the discovery of the variants in a single nucleotide in the DNA allow the development of methodologies for the identification from the amplification of DNA and its hybridization with probes that can hybridize or join variants of interest and thus determine the particular genotype of an individual (Frigolet and Gutiérrez-Aguilar, 2017). Therefore, to properly delimit a genetic epidemiology, all aspects of population genetics must be considered, except evolution. Incluying, the phenotype, the genetic-environmental interactions and modes of transmission that are related to health or the location of the genes responsible for causing the diseases (Khoury et al., 2004). Where the technological advance, the establishment of consortiums of DNA banks, the support of statistical tools and the reference of the human genome have given rise to the discovery of rare or common variants that predispose to the development of diseases (Begum et al., 2012).

The genetic has permitted the identification of some diseases with a Mendelian pattern of inheritance and the diseases that do not follow the Mendelian pattern known as common diseases (Frigolet and Gutierrez-Aguilar, 2017). Therefore, this is where genomic tools are essential for designing epidemiological studies, analysis and causal inference of environmental factors that are linked to a disease (Khoury and Yang, 1998). So that nutrigenomics can provide a molecular knowledge about the components of the diet that contribute to health through the alteration of the expression or structures depending on the individual genetic constitution (Corella and Ordovas, 2005).

\subsubsection{Transcriptomics}

This omic science is in charge of making the functional analysis of gene sequences, the analysis of messenger RNA, the activation (expression) and or the repression of genes (Clavijo and Fajardo, 2008). In other words, it is responsible for the study of gene expression profiles; simultaneous assessment of the expression levels of multiple genes in a given tissue at a specific time (Gironella, 2010).

At the cellular level, the genetic information encoded in the DNA and contained in the genes is expressed through the mechanisms of transcription and translation, a process that leads to the formation of mRNA and protein molecules (Soto and Lopez, 2012). In this sense, the control of the response to situations of biotic and abiotic stress is controlled by the transcriptional activation of the activation or repression of genes (Proudfoot et al., 2002). Thus, the amount of molecules produced by a given mRNA depends on the function it has in a specific cellular process, to respond to certain conditions (Soto and Lopez, 2012).

In this way the determination of the exact place, form and moment when a transcript is generated, under a particular condition, is fundamental to understand the process of the biological activity of a gene (Soto and Lopez, 2012).

Currently, thanks to the incorporation of new generation technologies, in the fields of genomics and transcriptomics, for DNA sequencing, it has been possible to generate information with high yields and at low cost, which has also opened up new horizons for detailed understanding of the gene expression processes (Ward et al., 2012).

\subsubsection{Proteomics}

The proteomics is in charge of the deep study of the structure and functions of the proteome of a cell, tissue or biological liquid at a certain moment of the protein expression, its dynamic properties and its relationship with the genome (Clavijo and Fajardo, 2008). The proteome, is made up of all the proteins that are expressed from the genome of an organism (Wilkins et al., 1996). Unlike the genome, the proteome is a highly dynamic element that varies over time and is defined as the proteins present in a biological sample at a certain time (Kvasnicka, 2003). The alterations in their environment can cause changes in the proteome (Pando and Ferreira, 2008).

The proteomics science, allows to understand the functions and alterations of organelles, among other aspects (Bottoni et al., 2012). In addition, it is a central platform in nutrigenomics that describes the expression of the genome as a response to diet (Clavijo and Fajardo, 2008). Currently, with the known of the nucleotide sequence of genes it is possible to infer with certain reliability the proteins that are expressed from this genome (Pando and Ferreira, 2008).

The proteomics, can be divided into different branches that are responsible for the characterization of the proteome 
(Rizo et al., 2014). The expression proteomics is responsible for the description of the total proteome of a tissue, fluid, cell or organelle and quantitative measurements of the levels of protein expression. The functional proteomics studies the function of proteins within biological systems and the regulation of their expression (Pando and Ferreira, 2008). While, comparative proteomics is responsible for identifying differences at the level of protein expression that are associated with changes in the conditions of an organism (Castellanos et al., 2004).

Its main applications have been developed within the field of biology and medicine (Rizo et al, 2014). Where its applications are in areas such as the pathophysiology of diseases, screening for diseases, the prediction of response to drugs and the development of therapeutic targets (Milke-Garcia, 2012). The applications of proteomics in public health, focused on the study of DNA dysfunction and mutations, have succeeded in explaining a large number of diseases, including cancer (Pando-Robles and Lanz-Mendoza, 2009). Being especially useful for identifying proteins that participate in cellular signaling, differentiation and death (Milke-Garcia, 2012). The goodness of proteomics lies in its null invasiveness as they are based on the analysis of easily obtainable biological samples such as urine, blood and saliva in exchange for obtaining ample information (Kussmann et al., 2006).

Some proteins identified in the diabetes disease show changes in differential expression in the pancreas (Petyuk et al., 2008), skeletal muscle (Mullen et al., 2011), heart (Cai et al., 2013), adipose tissue (Boden et al., 2008) and liver (Valle et al., 2012), and have been related to obesity, insulin resistance and type 2 diabetes mellitus. This important information serve to understand the mechanisms that lead to diabetes mellitus type 2 and its complications (Jimenez-Flores et al., 2014).

\subsubsection{Metabolomics}

Metabolomics is the science that seeks to analyze the systematic study of the final chemical processes of metabolism, in which metabolites intervene as unambiguous and specific signals of cellular processes (Daviss, 2005). Including the impact on cellular metabolism and intermediaries based on the genetic information (Clavijo and Fajardo, 2008). In other words, it is a dynamic portrait of the metabolic state of living systems (Claudino et al., 2007). For its part, the metabolome is composed of a large number of metabolites consisting of small molecules and products of cellular processes, which exhibit a variety of physical and chemical properties, which exist within a very wide dynamic range in our cells, tissues, organs and organisms (Tolstikov, 2009).

Metabolomics is based on the use of mass spectrometry to investigate the biochemical mechanisms related to natural processes in health and disease (Milke-García, 2012). However, physiological and pathological conditions are not only characterized by the identities and concentrations of metabolites present in food, but also by the location of these in a tissue (Tolstikov, 2009). Therefore, the most recent developments in image-mass spectrometry technologies allow certain metabolites to be recognized spatially within their tissues (Calavia et al., 2012).

The activities of a cell at a functional level can be illustrated through the characterization of metabolic pathways, (MilkeGarcia, 2012), however, the metabolome is difficult to characterize and therefore different separation techniques are required (Baidoo et al., 2012).

\section{The New Foods}

Foods constitute complex matrices, which have traditionally been studied from a chemical, physicochemical, microbiological and sensory perspective (Rizo et al, 2014).

Currently, the general public looking for minimally processed foods, quick to consume, easy to carry and healthy (Ashwell, 2004). In this sense, the application of proteomic tools would contribute in the search for new functional bioactive compounds; the evaluation of the safety of the ingredients that make up the food; the detection and control of natural deterioration of natural foods or caused by pathogenic microorganisms; the identification of biomarkers and proteins that cause allergies; the quality and authenticity of foods; the production of food ingredients and; food processing (Kvasnicka, 2003). Can be mentioned that the perspective of the consumer, many classifications have emerged about healthy foods different to the concepts of functional foods and organic foods (Garcia-Casal, 2007).

\subsection{Functional foods}

In the 80s in Japan, the concept of functional foods arises and until 1999 was defined that a functional food contains a component, nutrient or not nutrient, with selective effect on one or more functions of the organism, with an added effect over its nutritional value and whose positive effects can vindicate its functional or even healthy character (Ashwell, 2004). Some examples of functional foods are natural foods with certain minerals, vitamins, fatty acids, phytosterols, fiber, antioxidants. This classification included foods modified, enriched and probiotics such as yogurt (Aggett et al., 1999). The trends in the development of functional foods include the calorie content reduction, the development products with lower fat content or with healthier fats, low glycemic index products, among others (Garcia-Casal, 2007). Also, we can mention the studies on phytoestrogens and phytosterols, fructooligosaccharides, polyphenols and omega 3 fatty acids (Nijveldt et al., 2001).

\subsection{Organic, biological or ecological foods}

An organic food is one that takes care of both the health of consumers and the balance of the environment in which it is produced (García-Casal, 2007). Their success is due to the fact that they are considered healthier and safer (National Research Council, 1993) by the low or no load of pesticides 
used for its production (Alavanja et al., 2004). Although the food consumption of these has skyrocketed in recent years, mainly in European countries, their benefits have been questioned in terms of biosecurity and cost (Krebs, 2003), especially for the efficiency and safety of newly developed pesticides (Garcia-Casal, 2007).

\subsection{Transgenic foods}

Genetics has been applied in food since the beginning of agriculture and livestock, empirically improving the genome of edible plant varieties, animal breeds and ferments. This improvement has been based on the appearance of spontaneous mutants, natural variability and the application of sexual crossing or hybridization. More recently, scientists have isolated specific fragments, in the laboratory, that carry certain genes, which can vary in the test tube and can be reintroduced into the natural organism or into a different organism generating a transgenic one, and when applied in the design of a food arise the so-called transgenic foods (Vidal, 2009).

Today, many transgenic foods are commercialized worldwide, mainly in the United States of America, Australia, Canada and China. Where, the best known are soybeans resistant to the herbicide glyphosate and corn Bt, which has the "Cry" protein derived from Bacillus thuringiensis, which is toxic to the larvae of the stem borer insects (Broderick et al., 2006). Despite some environmental organizations accuse transgenic foods of being a poison for health and the environment. Another organizations such as FAO, OECD and WHO that have established working groups to evaluate consumer safety. However, there is no scientific data so far that indicates that they represent a risk to the health of the consumer (Vidal, 2009).

\section{Effect of Nutrients on Transcription Factors}

The use of genetics in food has been applied since the beginning of agriculture and livestock. The genes expression is controlled by proteins called nuclear receptors (NRs) which can be associated with various ligands such as glucocorticoids, mineralocorticoids, and sex and or thyroid hormones, among others (Sanhueza and Valenzuela, 2012). The NRs are divided into three types: i) endocrine, ii) orphans and, iii) adopted orphans, where the latter are preferably found in the nucleus and are of great biomedical and pharmacological interest (Alaynick, 2008).

Typically, a nuclear receptor is formed by three domains, related to the interaction with DNA (DBD), with a ligand (LBD) and with functional activators of transcription (AF), respectively. The RNs are linked to DNA sectors known as response elements (RE), activators and or specific inhibitors and ligands. The most common RNs are peroxisome proliferators (PPARs), X farnesoids (FXRs), hepatic X (LXRs), retinoic acid (RXRs), hepatic nuclear factor (HNF), and steroidal hormones (SREBP) in its different isoforms (Sanhueza and
Valenzuela, 2012). Of these NRs, more attention has been paid to PPARs, comparative studies of their functionality in several species have been carried out, being able to identify response elements for most known PPARs (Phelps et al., 2006). PPARs can interact with different organic molecules such as carbohydrates, proteins, lipids and some amino acids. Existing in some cases for example, a relationship with the metabolism of lipids (Cavalieri et al., 2009).

\subsection{Fatty acids}

It has been shown that several fatty acids have regulatory effects through the nuclear receptor kappa $b$ (NF-kB), which contains a p50 trimer, p65 and a factor IkB (Sanhueza and Valenzuela, 2012). When the IkB monomer is phosphorylated, the resulting dimer moves from the cytoplasm to the nucleus, where it interacts with specific genes, whose transcription products participate in inflammation processes or are factors that promote necrosis or hyperglycemia (De Martin et al., 2000). A negative response is given when the saturated fatty acids activate NF-kB; for its part, mono and polyunsaturated fatty acids inhibit this activation, resulting in a decrease in cardiovascular disorders (Bellido et al., 2004).

In individuals with high obesity, it has been observed that 239 genes are differentially expressed, compared to the 73 that are expressed in individuals with light obesity (Radonjic et al., 2009). Reason why, in a personalized diet should be considered that fats are not a predominant nutrient. In addition, it has been shown that the expression of leptin receptors, in a non-isocaloric high fat diet, is specific sex (Priego et al., 2009). This sexual dimorphism, in the expression of the leptin receptor, may be due to testosterone, since this hormone decreases the expression of the receptor mRNA in Leydig cells (Ishikawa et al., 2007).

\subsection{Carbohydrates}

Carbohydrates modulate genes through the carbohydrate response elements (ChREBP), in this way, the liver determines whether carbohydrates go towards a glycogen pathway or if enzymes necessary for lipogenesis are expressed (Yamashita et al., 2001). The activation of ChREBP is promoted with high levels of carbohydrates and inactivation occurs with low levels (Fukasawa et al., 2010). Lipogenesis in the liver is regulated by the transcription factor XBP-1 (Sanhueza and Valenzuela, 2012). In this sense, it has been observed that a diet rich in carbohydrates increases the expression of this protein in mice, which is why it is postulated that XBP-1 has an important role in human dyslipidemia (Lee et al., 2008).

\subsection{Proteins}

Although proteins do not exert a direct regulatory role on genes, some amino acids can regulate gene expression. Also, a low input of essential protein amino acids triggers a decrease in the synthesis of nor-epinephrine and CAMP, which alters protein synthesis (Zhang et al., 2002). This system works by means of a protein called CHOP, which binds with gene 
expression enhancers, and is activated by means of stressful stimuli such as DNA damage (Luethy and Holbrook, 1992). In addition to these factors, there are amino acid response elements (AARE) that are sensitive to nutrients (Jousse et al., 2004). Which, can regulate the initiation phase of protein synthesis by means of the initiation factor elF2 $\alpha$ (Kimball and Jefferson, 2004). Also, it has been observed that there is a differential expression of various proteins, depending on whether the mother receives a proper diet or low in protein, during pregnancy (McNeil et al., 2009).

\subsection{Vitamins}

The fat-soluble vitamins $A, D, E$ bind to RN by modulating specifically the expression of genes linked to energy metabolism (Wise and Kaput, 2009). The antioxidant activity of vitamin $E$ is known; however, in high amounts this vitamin can be procarcinogenic (Birringer et al., 2001). Other nutrigenomic studies, carried out on mice supplemented with beta-carotene, show that the carotenoid stimulates the G-protein coupled receptors (GPCRs) and also activates genes that are related to the remodeling of the extracellular matrix by the metalloproteinase enzymes, resulting in a restructuring of the cytoskeleton (Razny et al., 2010). On the other hand, the low intake of folic acid during pregnancy causes the substitution of thymine for uracil in the DNA, in addition to producing an abnormal pattern of chromatin methylations (Ma et al, 1997). On the contrary, the adequate supply of this vitamin allows the expression of the enzyme methylenetetrahydrofolate reductase (MTHFR) responsible for correctly performing methylations in specific sectors of chromatin (Kim, 1999).

\subsection{Minerals}

Minerals affect the transcription of genes, increasing or decreasing their expression. For example, in the intestinal epithelium, copper interacts with clover proteins (TFF1), which, if in their homodimer state, favor the formation of tumors and copper predisposes the TFF1 protein to acquire the heterodimeric state with antitumor effect (Tosco et al., 2010a). On the other hand, it has been seen that iron and calcium have opposite effects for the expression of proteins related to carcinogenic processes (Sesink et al., 2001). Where, the iron would favor the formation of tumors, increasing the carcinogenic cytotoxicity and the calcium would inhibit it, due to the induction of the pentatraxin gene of the mucosa (van der Meer-Van et al., 2005). On the other hand, the moderate deficiency of copper and iron for prolonged periods causes alterations in lipid metabolism, as well as deleterious effects in the cardiovascular system (Tosco et al., 2010b). Another mineral with important effects on organic physiology, is selenium, since it interacts with several proteins that are regulated by this mineral (Sanhueza and Valenzuela, 2012). For example, in prostate cancer it has been observed that of a total of 12,000 genes studied 2,500 respond to this mineral in this condition (Dong et al., 2003). Being able to modulate the progress of the cancer or to restrain it, by means of the suppression of tumors or by the expression of factors of growth of tumors, cellular invasion or adhesion, or of repair of the DNA (Davis and Milner, 2004).

\section{Conclusion}

The future of genetics applied to food is important, because new technologies focused on food require the intervention of new professionals from other fields of science, who understand the importance of biotechnology and genetics. On the other hand, thanks to technological advances and the contribution of the different omic sciences as well as the creation of several gene banks, has allowed to increase the existing information pool on biological molecules analyzed by multidisciplinary teams.

\section{Acknowledgement}

The authors would like to thank the Program for Professional Development Teacher (PRODEP), for funding the project.

\section{References}

Abraham, S.C., Park, S.J., Cruz-Correa, M., Houlihan, P.S., Half, E.E., Lynch, P.M., Wu, T.T., 2004. Frequent CpG island methylation in sporadaic and syndromic gastric fundic gland polyps. American Journal of Clinical Pathology 122(5), 740-746.

Afman, L., Muller, M., 2006. Nutrigenomics: from molecular nutrition to prevention of disease. Journal of the American Dietetic Association 106(4), 569-576.

Aggett, P., Ashwell, M., Bornet, F., Diplock, A., Fern, E., Roberfroid, M., 1999. Scientific Concepts of Functional Foods in Europe: Consensus Document. British Journal of Nutrition 81(Suppl. 1), S1-S27.

Alavanja, M., Hoppin, J., Kamel, F., 2004. Health effecfts of chronic pesticide exposure: cancer and neurotoxicity. Annual Review of Public Health 25, 155-197.

Alaynick, W.A., 2008. Nuclear receptors, mitochondria and lipid metabolism. Mitochondrion 8, 329-337.

Ashwell, M., 2004. Conceptos sobre los alimentos funcionales. International Life Science Institute (ILSI). ILSI Press. Washington DC, 48.

Baidoo, E.E., Benke, P.I., Keasling, J.D., 2012. Mass spectrometry-based microbial metabolomics. Methods in Molecular Biology 881, 215-278.

Bellido, C., Lopez-Miranda, J., Blanco-Colio, L.M., PerezMartinez, P., Muriana, F.J., Martin-Ventura, J.L., Marin, C., Gomez, P., Fuentes, F., Egido, J., Perez-Jimenez, F., 2004. Butter and walnuts, but not olive oil, elicit postprandial activation of nuclear transcription factor kappaB in peripheral blood mononuclear cells from healthy men. The American Journal of Clinical Nutrition 80, 1487-1491.

Begum, F., Ghosh, D., Tseng, G.C., Feingold, E., 2012. Comprehensive literature review and statistical 
considerations for GWAS meta-analysis. Nucleic Acids Research 40(9), 3777-3784.

Birringer, M., Drogan, D., Brigelius-Flohe, R., 2001. Tocopherols are metabolized in HepG2 cells by side chain omega oxidation and consecutive beta-oxidation. Free Radical Biology and Medicine 31, 226-232.

Boden, G., Duan, X., Homko, C., Molina, E.J., Song, W.W., Perez, O., Cheung, P., Merali, S., 2008. Increase in endoplasmic reticulum stress-related proteins and genes in adipose tissue of obese, insulin-resistant individuals. Diabetes 57, 2438-2444.

Bottoni, P., Giardina, B., Pontoglio, A., Scara, S., Scatena, R., 2012. Mitochondrial proteomic approaches for new potential diagnostic and prognostic biomarkers in cancer. Advances in Experimental Medicine and Biology 942, 423-440.

Broderick, N., Raffa, K., Handelsman, J., 2006. Midgut bacteria required for Bacillus thuringiensis insecticidal activity. Proceedings of the National Academy of Sciences 103, 15196-15199.

Burguete, A., Bermudez-Morales, V.H., Madrid-Marina, V., 2009. Medicina genomica aplicada a la salud pública. Salud Pública de México 51(Supl 3), S379-S385.

Cai, Q., Li, B., Yu, F., Lu, W., Zhang, Z., Yin, M., Gao, H., 2013. Investigation of the Protective Effects of Phlorizin on Diabetic Cardiomyopathy in $\mathrm{db} / \mathrm{db}$ Mice by Quantitative Proteomics. Journal of Diabetes Research 2013, 263845.

Calavia, R., Annanouch, F.E., Correig, X., Yanes, O., 2012. Nanostructure initiator mass spectrometry for tissue imaging in metabolomics: future prospects and perspectives. Journal of Proteomics 75(16), 5061-5068.

Claudino, W.M., Quattrone, A., Biganzoli, L., 2007. Metabolomics: available results, current research projects in breast cancer, and future applications. Journal of Clinical Oncology 25, 2840-2846.

Carpenter, K.J., 2003a. A short History of Nutritional Science: Part 1 (1785-1885). The Journal of Nutrition 133(3), 638-645.

Carpenter, K.J., 2003b. A short History of Nutritional Science: Part 2 (1885-1912). The Journal of Nutrition 133(4), 975-984.

Carpenter, K.J., 2003c. A short History of Nutritional Science: Part 3 (1912-1944). The Journal of Nutrition 133(10), 3023-3032.

Carpenter, K.J., 2003d. A short History of Nutritional Science: Part 4 (1945-1985). The Journal of Nutrition 133(11), 3331-3342.

Castellanos, L.G., Gonzalez, J.L., Padron, G., 2004. Proteomica. In: Vispo, N.S. (Ed.), Combinatoria Molecular. Elfos Scientiae. La Habana, 367-403.

Castle, D., Ries, N.M., 2007. Ethical, legal and social issues in nutrigenomics: the challenges of regulating service delivery and building health professional capacity. Mutation Research 622(1-2), 138-143.
Cavalieri, D., Calura, E., Romualdi, C., Marchi, E., Radonjic, M., Van Ommen, B., Müller, M., 2009. Filling gaps in PPARalpha signaling through comparative nutrigenomics analysis. BMC Genomics 10, 596.

Clavijo, H.A., Fajardo, L.F., 2008. Neurobiologia, alimentacion y vida saludable: Parte II. Los desafíos de la nutrigenómica. Revista Digital de Psicologia 3(3), 76-94.

Cooper, R.S., Psaty, B.M., 2003. Genomics and medicine: distraction, incremental progress, or the dawn of a new age? Annals of Internal Medicine 138, 576-580.

Corella, D., Ordovas, J.M., 2005. Single nucleotide polymorphisms that influence lipid metabolism: Interaction with dietary factors. Annual Review of Nutrition 25, 341-390.

Corella, D., 2016. Las ciencias ómicas y la promoción de la salud en el siglo XXI. In Sesión Científica Extraordinaria. Available from http://www.fesnad.org/resources/files/ Cursos/cienciasOmicas24Nov.pdf.

Daniel, H., 2002. Genomics and proteomics: importance for the future of nutrition research. British Journal of Nutrition 87(Supl.2), S305-S311.

Daviss, B., 2005. Growing pains for metabolomics. The Scientist 19, 25-28.

Davis, C.D., Milner, J., 2004. Frontiers in nutrigenomics, proteomics, metabolomics and cancer prevention. Mutation Research 551, 51-56.

de las Cagigas, R.A., Ferreira, R., Tam, M., 2002. Biología Molecular y Nutricion. Revista Cubana de Alimentación y Nutrición 16, 69-76.

De Martin, R., Hoeth, M., Hofer-Warbinek, R., Schmid, J.A., 2000. The transcription factor NF-kappa $B$ and the regulation of vascular cell function. Arteriosclerosis Thrombosis and Vascular Biology 20, E83-E88.

Dong, Z., 2000. Effects of food factors on signal transduction pathways. Biofactors 12, 17-28.

Dong, Y., Zhang, H., Hawthorn, L., Ganther, H.E., Ip, C., 2003. Delineation of the molecular basis for seleniuminduced growth arrest in human prostate cancer cells by oligonucleotide array. Cancer Research 63, 52-59.

El-Sohemy, A., Stewart, L., Khataan, N., Fontaine-Bisson, B., Kwong, P., Ozsungur, S., Cornelis, M.C., 2007. Nutrigenomics of taste - impact on food preferences and food production. Forum of Nutrition 60, 176-182.

Esteva De S.J., 2003. La secuencia del genoma humano. Offarm 22(9), 11.

Fabiani, E., Leone, G., Giachelia, M., Dalo, F., Greco, M., Criscuolo, M., Guidi, F., Rutella, S., Hohaus, S., Voso, M.T., 2010, Analysis of genome-wide methylation and gene expression induced by 5 -aza- 2 -deoxycytidine identifies BCL2L10 as a frequent methylation target in acute myeloid leukemia. Leukemia \& Lymphoma 51(12), 2275-2284.

Fletcher, M.A., Low, K.A., Boyd, R., Zimmerman, B., Gordon, B.A., Tan, C.H., Schneider-Garces, N., Sutton, B.P., 
Gratton, G., Fabiani, M., 2016. Comparing aging and fitness effects on brain anatomy. Frontiers in Human Neuroscience 10(286), 1-15.

Frigolet, M.E., Gutierrez-Aguilar, R., 2017. Ciencias “omicas", ¿como ayudan a las ciencias de la salud?. Revista Digital Universitaria, 18(7), 1-11.

Fujii, T.M.M., Medeiros, R., Yamada, R., 2010. Nutrigenomics and nutrigenetics: important concepts for the science of nutrition. Nutrire: Journal of the Brazilian Society of Food and Nutrition 35(1), 149-166.

Fukasawa, M., Ge, Q., Wynn, R.M., Ishii, S., Uyeda, K., 2010. Coordinate regulation/localization of the carbohydrate responsive binding protein (ChREBP) by two nuclear export signal sites: Discovery of a new leucine-rich nuclear export signal site. Biochemical and Biophysical Research Communications 391, 1166-1169.

García, F., 2004. La genomica nutricional: un nuevo paradigma de la investigacion de la nutricion humana. Colombia Médica 35(3), 150-160.

García-Casal, M.N., 2007. La alimentación del futuro: Nuevas tecnologías y su importancia en la nutrición de la poblacion. Anales Venezolanos de Nutricion 20(2), 108-114.

Gillies, P.J., 2003. Nutigenomics: the rubicon of molecular nutrition. Journal of the American Dietetic Association 103(12 Supl. 2), S50-S55.

Gironella, C.M., 2010. Nuevos metodos de diagnostico molecular, Transcriptomica (mARN y miR). GH Continuada 9(4), 160-164.

Hocquette, J.F., 2005. Where are we in genomics. Journal of Physiology and Pharmacology 56(3), 37-70.

Holtzman, N.A., 1988. Genetic variation in nutritional requirements and susceptibility to disease: policy implications. The American Journal of Clinical Nutrition 48, 1510-1516.

International Human Genome Sequencing Consortium, 2004. Finishing the euchromatic sequence of the human genome. Nature 431, 931-945.

Ishikawa, T., Fujioka, H., Ishimura, T., Takenaka, A., Fujisawa, M., 2007. Expression of leptin and leptin receptor in the testis of fertile and infertile patients. Andrologia 39, 22-27.

Jimenez-Flores, L.M., Flores-Perez, E.C., Mares-Alvarez, D.P., Macías-Cervantes, M.H., Ramírez-Emiliano, J., PérezVázquez, V., 2014. Aportaciones de la proteómica en el estudio de la diabetes. Gaceta Médica de México 150, 88-94.

Jousse, C., Averous, J., Bruhat, A., Carraro, V., Mordier, S., Fafournoux, P., 2004. Amino acids as regulators of gene expression: molecular mechanisms. Biochemical and Biophysical Research Communications 313, 447-452.

Kaput, J., Rodriguez, R.L., 2004. Nutritional genomics: the next frontier in the postgenomic era. Physiological Genomics 15(16), 166-177.
Khoury, M.J., Millikan, R., Little, J., Gwinn, M., 2004. The emergence of epidemiology in the genomics age. International Journal of Epidemiology 33, 936-944.

Khoury, M.J., Yang, Q., 1998. The future of genetic studies of complex human diseases: an epidemiologic perspective. Epidemiology 9, 350-354.

Killian, J.K., Byrd, J.C., Jirtle, J.V., Munday, B.L., Stoskopf, M.K., MacDonald, R.G., Jirtle, R.L., 2000. M6P/IGF2R imprinting evolution in mammals. Molecular Cell 5(4), 707-716.

Kim, Y.I., 1999. Folate and carcinogenesis: evidence, mechanisms, and implications. The Journal of Nutritional Biochemistry 10, 66-88.

Kimball, S.R., Jefferson, L.S., 2004. Amino acids as regulators of gene expression. Nutrition and Metabolism 1, 3.

Kliewer, S.A., Xu, H.E., Lambert, M.H., Willson, T.M., 2001. Peroxisome proliferator-activated receptors: from genes to physiology. Recent Progress in Hormone Research $56,239-263$.

Krebs, J., 2003. Is organic food better for you? Food Standards Agency. Available from www.food.gov.uk.

Kussmann, M., Raymond, F., Alfolter, M., 2006. OMICS-driven biomarker discovery in nutrition and health. Journal of Biotechnology 124, 758-787.

Kvasnicka, F., 2003. Proteomics: general strategies and application to nutritionally. Journal of Chromatography B 787, 77-89.

Lee, A.H., Scapa, E.F., Cohen, D.E., Glimcher, L.H., 2008. Regulation of Hepatic Lipogenesis by the Transcription Factor XBP1. Science 320(5882), 1492-1496.

Lin, S.J., Guarente, L., 2003. Nicotinamide adenine dinucleotide, a metabolic regulator of transcription longevity and disease. Current Opinion in Cell Biology 15, 241-246.

Loktionov, A., 2003. Common gene polymorphisms and nutrition: emerging links with pathogenesis of multifactorial chronic diseases (review). The Journal of Nutritional Biochemistry 14, 426-451.

Long, M., de Souza, S.J., Gilbert, W., 1995. Evolution of the intron-exon structure of eukaryotic genes. Current Opinion in Genetics and Development 5, 774-778.

Lopez-Lopez, M., Lopez, G.A.U., Sainz, E.T.delR., Rosales, T.A.M., 2005. ¿Que sabe usted acerca de...Genomica? Revista mexicana de Ciencias Farmacéuticas 36(1), 42-44.

Luethy, J.D., Holbrook, N.J., 1992. Activation of the gadd153 promoter by genotoxic agents: a rapid and specific response to DNA damage. Cancer Research 52, 5-10.

Ma, J., Stampfer, M., Giovannucci, E., Artigas, C., Hunter, D.J., 1997. Methylenetetrahydrofolate reductase polymorphism, dietary interactions, and risk of colorectal cancer. Cancer Research 57, 1098-1102.

Marti, M.A., Moreno-Aliaga, J., Zulet, A.M., Martínez, A.J., 2005. Avances en nutrición molecular: nutrigenómica y/o nutrigenética. Nutrición Hospitalaria 20, 157-164. 
McNeil, C.J., Hay, S.M., Rucklidge, G.J., Reid, M.D., Duncan, G.J., Rees, W.D., 2009. Gene and protein expression profiles in the foetal liver of the pregnant rat fed a low protein diet. Genes and Nutrition 4, 189-194.

Mensink, R.P., Plat, J., 2002. Post-genomic opportunities for understanding nutrition: the nutritionist's perspective. Proceedings of the Nutrition Society 61, 401-404.

Milke-Garcia, M.P., 2012. Nutrigenómica, proteómica y metabolómica en la prevencion y tratamiento de las enfermedades gastrointestinales. Revista de Gastroenterología de Mexico 77(1), 29-31.

Mullen, E., O’Reilly, E., Ohlendieck, K., 2011. Skeletal muscle tissue from the Goto-Kakizaki rat model of type-2 diabetes exhibits increased levels of the small heat shock protein Hsp27. Molecular Medicine Reports 4, 229-236.

Mutch, D.M., Wahli, W., Williamson, G., 2005. Nutrigenomics and nutrigenetics: the emerging faces of nutrition. The Faseb Journal 19(12), 1602-1616.

National Research Council, 1993. Pesticides in the diets of infants and children. National Academies Press. Washington DC, 386.

Nijveldt, R.J., van Nood, E., van Hoorn, D.E., Boelens, P.G., van Norren, K., van Leeuwen, P.A., 2001. Flavonoids: a review of probable mechanisms of action and potential applications. The American Journal of Clinical Nutrition 74(4), 418-425.

Nobel, S., Abrahmsen, L., Oppermann, U., 2001. Metabolic conversion as a pre-receptor control mechanism for lipophilic hormones. European Journal of Biochemistry 268(15), 4113-4125.

NUGO (European Nutrigenomics Organization), 2004. What is NUGO?. Available from http://www.nugo.org/ everyone/24017.

Ordovas, J.M., Mooser, V., 2004. Nutrigenomics and nutrigenetics: editorial review. Current Opinion in Lipidology 15(2), 101-108.

Ordovas, J.M., Carmena, R., 2005. Nutrigenetica. Humanitas, Humanidades Medicas 9, 3-19.

Palou, A., Bonet, M., Pico, C., Rodriguez, A.M., 2004. Nutrigenomica y obesidad. Revista de Medicina de la Universidad de Navarra 48(2), 36-48.

Pando-Robles, R.V., Lanz-Mendoza, H., 2009. La importancia de la proteomica en la salud publica. Salud Publica de México 51, S386-S394.

Pando, R.V., Ferreira, B.C., 2008. Proteómica: Hacia el entendimiento del lenguaje de las proteínas. In: Lopez, M.A. (Ed.), A Una Ventana al Quehacer Científico, Instituto de Biotecnologia, Mexico, 97-108.

Perdomo, S., Cardenas, D., 2011. El surgimiento de las ciencias "omicas" en nutrición: una necesidad actual. Revista de Metabolismo y Nutricion Clínica 2(1), 54-58.

Priego, T., Sanchez, J., Palou, A., Picó, C., 2009. Effect of highfat diet feeding on leptin receptor expression in white adipose tissue in rats: depot- and sex-related differential response. Genes and Nutrition 4, 151-156.

Proudfoot, N., Furger, A., Dye, M., 2002. Integrating mRNA Processing with Transcription. Cell 108, 501-512.

Petyuk, V.A., Qian, W.J., Hinault, C., Gritsenko, M.A., Singhal, M., Monroe, M.E., Camp, D.G., Kulkarni, R.N., Smith, R.D., 2008. Characterization of the mouse pancreatic islet proteome and comparative analysis with other mouse tissues. Journal of Proteome Research 7, 3114-3126.

Phelps, C., Gburcik, V., Suslova, E., Dudek, P., Forafonov, F., Bot, N., MacLean, M., Fagan, R.J., Picard, D., 2006. Fungi and animals may share a common ancestor to nuclear receptors Proceedings of the National Academy of Sciences of the United States of America 103, 7077-7081.

Radonjic, M., van Erk, M.J., Pasman, W.J., Wortelboer, H.M., Hendriks, H.F., van Ommen, B., 2009. Effect of body fat distribution on the transcription response to dietary fat interventions. Genes and Nutrition 4, 143-149.

Razny, U., Polus, A., Kiec-Wilk, B., Wator, L., Hartwich, J., Stachura, J., Tomaszewska, R., Dyduch, G., Laidler, P., Schmitz, G., Goralczyk, R., Wertz, K., Riss, G., Franssenvan Hal, N.L., Keijer, J., Dembinska-Kiec, A., 2010. Angiogenesis in Balb/c mice under beta-carotene supplementation in diet. Genes and Nutrition 5, 9-16.

Rivera, W.C., 2002. El Genoma Humano. Revista Médica Hondurena 70, 132-137.

Rizo, J., Cardenas, C., Rodriguez-Sanoja, R., 2014. Los Alimentos: una Aproximación proteómica en su Estudio. BioTecnologia 18, 30-45.

Saini, S., Majid, S., Dahiya, R., 2010. Diet, microRNAs and prostate cancer. Pharmaceutical Research 27, 10141026.

Sanhueza, J., Valenzuela, A.B., 2012. Nutrigenómica: Revelando los aspectos moleculares de una nutricion personalizada. Revista Chilena de Nutricion 39, 71-85.

Sesink, A.L.A., Termont, D.S., Kleibeuker, J.H., Van der, M.R., 2001. Red meat and colon cancer: dietary haem-induced colonic cytotoxicity and epithelial hyperproliferation are inhibited by calcium. Carcinogenesis 22, 1653-1659.

Silleras, M., Torres, M., 2000. Nutrition and gene expresión. Nutricion Hospitalaria 15(Suppl 1), 128-142.

Soto, S.J.C., Lopez, C.C.E., RNA-seq: herramienta transcriptómica útil para el estudio de interacciones planta-patogeno. Fitosanidad 16, 101-113.

Stover, P.J., 2004. Nutritional genomics. Physiological Genomics 16, 161-165.

Svacina, S., 2007. Nutrigenetics and nutrigenomics. Casopis Lekaur Ceskych/Journal of Czech Physicians 146(11), 837-839.

Tolstikov, V.V., 2009. Metabolic analysis. Methods in Molecular Biology 544, 343-353.

Tosco, A., Monti, M.C., Fontanella, B., Montefusco, S., D’Andrea, L., Ziaco, B., Baldantoni, D., Rio, M.C., 
Marzullo, L., 2010a. Copper binds the carboxy-terminus of trefoil protein 1 (TFF1), favoring its homodimerization and motogenic activity. Cellular and Molecular Life Sciences 67, 1943-1955.

Tosco, A., Fontanella, B., Danise, R., Cicatiello, L., Grober, O.M., Ravo, M., Weisz, A., Marzullo, L., 2010b. Molecular bases of copper and iron deficiency-associated dyslipidemia: a microarray analysis of the rat intestinal transcriptome. Genes and Nutrition 5, 1-8.

Vakili, S., Caudill, M.A., 2007. Personalized nutrition: nutritional genomics as a potential tool for targeted medical nutrition therapy. Nutrition Reviews 65(7), 301-315.

Valle, A., Catalan, V., Rodriguez, A., Rotellar, F., Valenti, V., Silva, C., Salvador, J., Frühbeck, G., Gómez-Ambrosi, J., Roca, P., Oliver, J., 2012. Identification of liver proteins altered by type 2 diabetes mellitus in obese subjects. Liver International 32, 951-961.

van der Meer-Van K.C., Kramer, E., Jonker-Termont, D., Katan, M.B., van der Meer, R., Keijer, J., 2005. Differential gene expression in rat colon by dietary heme and calcium. Carcinogenesis 26, 73-79.

Venter, J.C., Adams, M.K., Myeres, E.W., Li, P.W., Mural, R.J., et al. 2001. The sequence of the human genome. Science 291(5507), 1304-1351.

Vidal, D.R., 2009. Transgenicos, nutrigenetica y nutrigenomica en alimentacion. Tecnología i Ciencia dels Aliments 11(1), 10-12.

Ward, J., Ponnala, L., Weber, C., 2012. Strategies for Transcriptome Analysis in Nonmodel Plants. American Journal of Botany 99, 267-276.

Willett, W.C., 2002. Balancing life-style and genomics research for disease prevention. Science 296, 695-698.
Wilkins, M.R., Sanchez, J.C., Gooley, A.A., Appel, R.D., Humphery-Smith, I., Hochstrasser, D.F., Williams, K.L., 1996. Progress with proteome projects: why all proteins expressed by a genome should be identified and how to do it. Biotechnology and Genetic Engineering Reviews 13, 19-50.

Wise, C., Kaput, J., 2009. A strategy for analyzing gene-nutrient interactions in type 2 diabetes. Journal of Diabetes Science and Technology 3, 710-721.

Withee, J., Dearfield, K.L., 2007. Genomics-based foodborne pathogen testing and diagnostics: Possibilities for the U. S. Department of Agriculture's Food Safety and Inspection Service. Environmental and Molecular Mutagenesis 48, 363-368.

Yaktine, A,L, Pool, R., 2007. Nutrigenomics and Beyond: Informing the Future-Workshop Summary, N.A.O. Sciences. The National Academy Press, Washington, D.C., 90.

Yamashita, H., Takenoshita, M., Sakurai, M., Bruick, R.K., Henzel, W.J., Shillinglaw, W., Arnot, D., Uyeda, K., 2001. A glucose-responsive transcription factor that regulates carbohydrate metabolism in the liver. Proceedings of the National Academy of Sciences of the United States of America 98, 9116-9121.

Zhang, X., Yap, Y., Wei, D., Chen, G., Chen, F., 2008. Novel omics technologies in nutrition research. Biotechnology Advances 26(2), 169-176.

Zhang, P., McGrath, B.C., Reinert, J., Olsen, D.S., Lei, L., Gill, S., Wek, S.A., Vattem, K.M., Wek, R.C., Kimball, S.R., Jefferson, L.S., Cavener, D.R., 2002. The GCN2 elF2 $\alpha$ kinase is required for adaptation to amino acid deprivation in mice. Molecular Cell Biology 22, 6681-6688. 